\title{
Anomalous origin of one pulmonary artery from the ascending aorta: a review of echocardiographic, catheter, and morphological features
}

\author{
LANCE V FONG, * ROBERT H ANDERSON, $†$ RALPH D SIEWERS, \\ ALFREDO TRENTO, SANG C PARK $\ddagger$ \\ From the ${ }^{*}$ Wessex Cardiothoracic Centre, Southampton General Hospital, Southampton; $\dagger$ National Heart \\ and Lung Institute, London; and $\ddagger$ Departments of Paediatrics and Surgery, University of Pittsburgh School of \\ Medicine, Children's Hospital of Pittsburgh, Pittsburgh, USA
}

SUMMARY Six patients with anomalous origin of one pulmonary artery from the ascending aorta were reviewed. Four had anomalous origin of the right pulmonary artery and two had anomalous origin of the left pulmonary artery from the ascending aorta. Two of these six patients had tetralogy of Fallot. Two patients died in the first month of life. No changes in the pulmonary vasculature were seen at necropsy. Corrective surgery was attempted in two patients with associated tetralogy of Fallot when they were two years old but both died. At necropsy there was severe pulmonary vascular disease in the lung supplied by the anomalous pulmonary artery but no pulmonary vascular hypertensive changes in the lung supplied by the pulmonary artery from the right ventricle. Two recent patients underwent successful anastomosis of the anomalous pulmonary artery to the main pulmonary artery at three months and one month and three weeks of age respectively. Intraoperative lung biopsy in the latter patient showed early changes in both lungs. Both echocardiography and cardiac catheterisation were used in the diagnoses. Systemic or suprasystemic pressures were found in the pulmonary artery arising from the right ventricle as well as the anomalous pulmonary artery in the three patients without tetralogy of Fallot.

Anomalous origin of a pulmonary artery from the ascending aorta is a distinct entity and differs from other aorto-pulmonary arterial connections. Early surgical intervention is recommended in all patients (including those patients with associated tetralogy of Fallot) because of the risk of rapid development of irreversible pulmonary vascular disease.

Anomalous origin of one pulmonary artery from the ascending aorta with the contralateral pulmonary artery arising from the right ventricle is a rare congenital cardiac abnormality. The lesion must be distinguished from other arrangements in which the origin of one pulmonary artery is atretic but the arterial supply is derived either from a ductus arteriosus (arterial duct) or via collaterals between the systemic and pulmonary arteries. ${ }^{12}$

We reviewed the detailed findings, including diagnostic data and surgical considerations, in six patients with direct origin of one pulmonary artery

Requests for reprints to Dr Lance V Fong, Wessex Cardiothoracic Centre, Southampton General Hospital, Southampton SO9 4XY.

Accepted for publication 4 July 1989 from the ascending aorta. The morphology seen in four hearts at necropsy and the histopathology of the pulmonary vasculature at necropsy or lung biopsy were also examined.

\section{Patients and methods}

STUDY PATIENTS

From January 1968 to July 1987, six patients (two male, four female) with anomalous origin of one pulmonary artery from the ascending aorta were seen at the Children's Hospital of Pittsburgh. Four patients presenting in the first two months of life with congestive cardiac failure had the right (three) or left (one) pulmonary artery arising from the ascending aorta. Diagnosis was made at necropsy in the earliest case and by echocardiography or cardiac catheterisa- 
tion in the others. Two patients presented with cyanosis and a murmur when they were six months old. They had tetralogy of Fallot with a right aortic arch and a right (one) or left (one) pulmonary artery arising from the ascending aorta. In all patients the other pulmonary artery arose from the right ventricle.

One patient (case 1) (table) had Down's syndrome with duodenal atresia and prematurity while another (case 2) had clinical findings of the Di George syndrome with absence of the thymus at necropsy. The other patients had no extracardiac abnormalities.

\section{DIAGNOSTIC STUDIES}

Echocardiography was performed in the two most recent patients before cardiac catheterisation and again in the postoperative period. Five patients underwent cardiac catheterisation. Diagnosis was made at necropsy in the first patient of the series. In all patients we measured the size of the pulmonary arteries at the hilum, the distance of the anomalous origin above the aortic valve, and the length of the anomalous pulmonary artery from its origin with the aorta to its branching point. These measurements were taken from angiograms except in the patient not undergoing cardiac catheterisation. In this patient measurements were taken from the necropsy specimen.

\section{COURSE}

Operation was not performed on the earliest two patients in the series (cases 1 and 2) (table) although diagnosis had been confirmed by cardiac catheterisa- tion in the second patient. Both died in the fifst month. Two other patients (cases 3 and 4) with tetralogy of Fallot underwent attempted surgical correction at 25 and 26 months of age but both die $i$ in the early postoperative period. Necropsy specimens of the heart and lung were available from these four patients. The last two patients in the series, who wre diagnosed by echocardiography and angiography, underwent successful operative repair at three

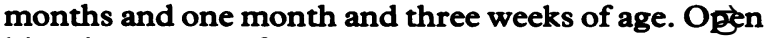
biopsies were performed on both lungs at the time-of surgical repair in one patient (case 6).

\section{Results}

\section{ECHOCARDIOGRAPHY}

The parasternal long axis view (fig la) showed anomalous posterolateral origin of the pulmonfyy artery from the ascending aorta a short distarce above the aortic valve. The ascending aorta and the anomalous pulmonary artery were more extensiv $7 y$ visualised with the transducer in a more cephafad position than that providing the usual long asis parasternal view. The ascending vessel above pulmonary artery was shown to continue as the aortic arch, confirming that the vessel was the aorta and the pulmonary artery. The size of the anomalois pulmonary artery was normal. Its course could be followed from suprasternal views by directing the transducer towards the right or left lung. The expected bifurcation of the pulmonary trunk coofld not be seen from either the parasternal or supiasternal short axis views (fig $1 \mathrm{~b}$ ). However, one patient had a large left atrial appendage which simulate $\bar{d}$

Table Data on six patients with anomalous origin of one pulmonary artery from the ascending aorta

\begin{tabular}{|c|c|c|c|c|c|c|c|c|c|}
\hline \multirow[b]{2}{*}{ Patient } & \multirow[b]{2}{*}{ Diagnosis } & \multicolumn{3}{|c|}{ Haemodynamic function ( $\mathrm{mm} \cdot \mathrm{Hg}$ ) } & \multicolumn{2}{|c|}{ Surgery (mnth) } & \multicolumn{2}{|c|}{ Lung histopathology } & \multirow{2}{*}{ Outcome } \\
\hline & & $\boldsymbol{R P} A$ & $L P A$ & $A O$ & Age & Type & Right & Left & \\
\hline 1 & $\begin{array}{l}\text { RPA-AO } \\
\text { DA }\end{array}$ & - & - & - & - & - & Normal & Normal & Dead $\frac{\sigma}{3}$ (3 wk) \\
\hline 2 & $\begin{array}{l}\text { RPA-AO } \\
\text { DA } \\
\text { LAA }\end{array}$ & $90 / 50$ & $105 / 55$ & $90 / 50$ & - & - & Normal & Normal & $\begin{array}{l}\text { Dead } \\
\text { (2 wk) }\end{array}$ \\
\hline 3 & $\begin{array}{l}\text { LPA-AO } \\
\text { TOF } \\
\text { RAA }\end{array}$ & $12 / 4$ & 一 & $110 / 60$ & 26 & $\begin{array}{l}\text { TOF repair, } \\
\text { LPA anastomosis }\end{array}$ & Normal & $\begin{array}{l}\text { Severe vascular } \\
\text { changes }\end{array}$ & $\begin{array}{l}\text { Dead } \frac{O}{2} \\
\text { (26 mnth) }\end{array}$ \\
\hline 4 & $\begin{array}{l}\text { RPA-AO } \\
\text { TOF } \\
\text { ALSA } \\
\text { RAA }\end{array}$ & $65 / 40$ & 一 & $100 / 40$ & 25 & Conduit to RPA & $\begin{array}{l}\text { Severe vascular } \\
\text { changes }\end{array}$ & Normal & Dead $\frac{\text { D }}{\text { (25 mnthis }}$ \\
\hline 5 & $\begin{array}{l}\text { LPA-AO } \\
\text { DA } \\
\text { ALSA } \\
\text { RAA }\end{array}$ & $90 / 40$ & - & $95 / 40$ & 3 & $\begin{array}{l}\text { LPA anastomosis, } \\
\text { DA ligation }\end{array}$ & - & 一 & Alive \\
\hline 6 & $\begin{array}{l}\text { RPA-AO } \\
\text { DA } \\
\text { LAA }\end{array}$ & - & $95 / 40$ & $75 /-$ & $1 \cdot 8$ & $\begin{array}{l}\text { RPA anastomosis, } \\
\text { DA ligation }\end{array}$ & $\begin{array}{l}\text { Early vascular } \\
\text { changes }\end{array}$ & $\begin{array}{l}\text { Early vascular } \\
\text { changes }\end{array}$ & Alive $\underset{\frac{0}{c}}{\frac{0}{(D)}}$ \\
\hline
\end{tabular}

ALSA, anomalous left subclavian artery; DA, ductus arteriosus; LAA, left aortic arch; LPA, left pulmonary artery; AO, ascending aorta; RAA, right aortic arch; RPA, right pulmonary artery; TOF, tetralogy of Fallot. 

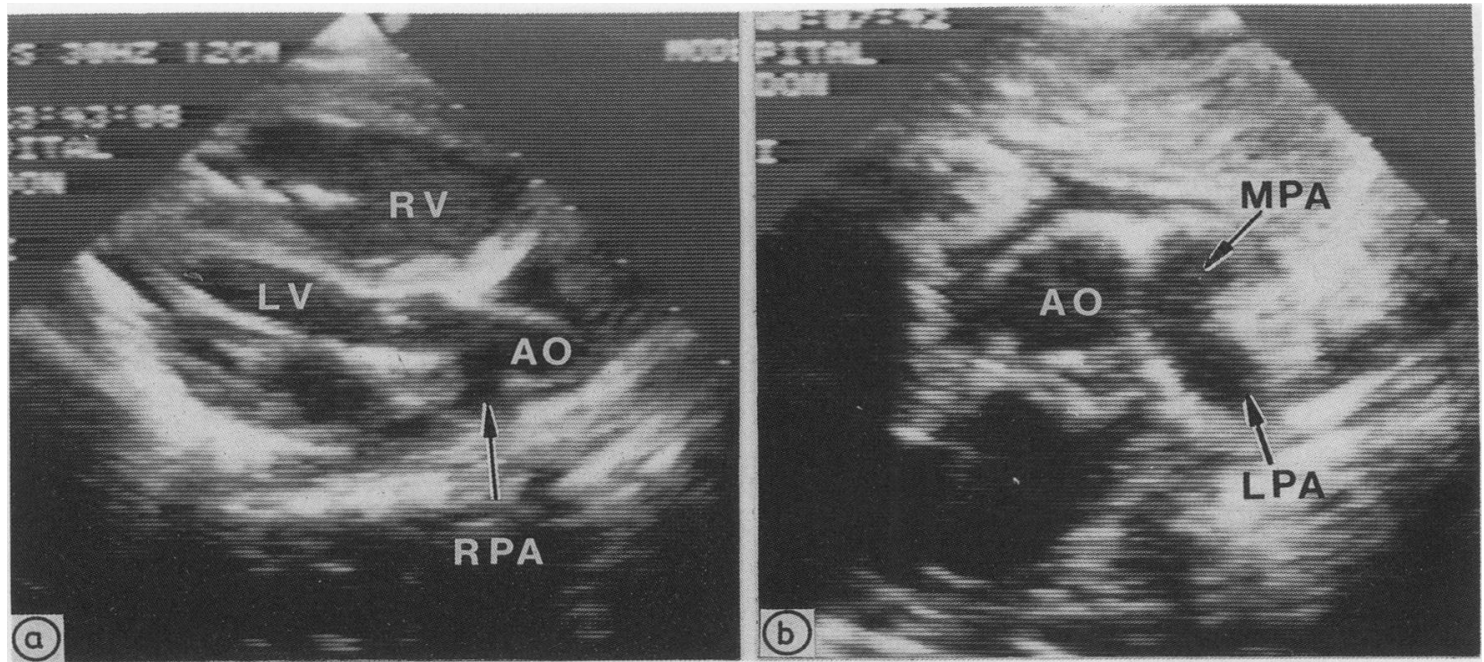

Fig 1 Echocardiograms. (a) Parasternal long axis view of the right pulmonary artery (RPA) arising posteriorly from t) ascending aorta (AO) (patient 6). (b) Suprasternal view of the left pulmonary artery (LPA) arising from the main pulmonary artery (MPA) (patient 6). LV, left ventricle; $R V$, right ventricle.

right pulmonary artery in parasternal views. The postoperative connection of the anomalous pulmonary artery to the pulmonary trunk was visualised in parasternal short axis views. It arose from a proximal surgically favourable position.

\section{HAEMODYNAMIC FUNCTION}

A low pressure in the pulmonary artery connected to the right ventricle was confirmed in patient 3 with tetralogy of Fallot (table). The left pulmonary artery arising from the right ventricle in the other patient (case 4) with tetralogy was not entered but the right ventricular outflow tract was considerably obstructed. An unexplained moderate pressure difference was found between the anomalous right pulmonary artery and aorta in the absence of stenosis at the origin of the anomalous pulmonary artery.

Pressures in the normally connected pulmonary artery were systemic or suprasystemic in all three patients $(2,5$, and 6$)$ in whom there was no right ventricular outflow obstruction. The anomalous pulmonary artery was not entered in two of these three patients, but the pressure in the artery was likely to be similar to that in the ascending aorta.

\section{OPERATION}

Both patients with tetralogy of Fallot underwent attempted surgical repair at 25 and 26 months of age. Under cardiopulmonary bypass and through a right ventriculotomy, repair in the first patient included resection of the subpulmonary infundibulum, closure of the ventricular septal defect, positioning a pericardial transannular patch, and detachment of the anomalous left pulmonary artery from the ascending aorta with direct anastomosis to the pulmonary trunk. In the other patient, who had a severely hypoplastic right ventricular outflow tract, a conduit was placed between the right ventricle and the detached anomalous right pulmonary artery, the ventricular septal defect was closed, and the subpulmonary infundibulum was resected. The hypoplastic left pulmonary artery was not incorporated into the conduit. The aortic defect was sutured directly. Both patients died soon after operation. Pressures in the right ventricle were persistently high and cardiac output poor.

The last two patients underwent successful operative detachment of the anomalous pulmonary artery from the ascending aorta with subsequent direct anastomosis to the pulmonary trunk. Operation was completed without cardiopulmonary bypass in one patient when the left pulmonary artery arose from the aorta. Both patients had an uneventful postoperative course.

\section{MORPHOLOGY}

The anomalous pulmonary artery originated from the posterolateral aspect of the ascending aorta between 5 and $20 \mathrm{~mm}$ from the aortic valve (fig $2 \mathrm{a}$ and b). In two patients the anomalous right pulmonary artery arose from the posterior left aspect of the ascending aorta and then passed behind the aorta to 

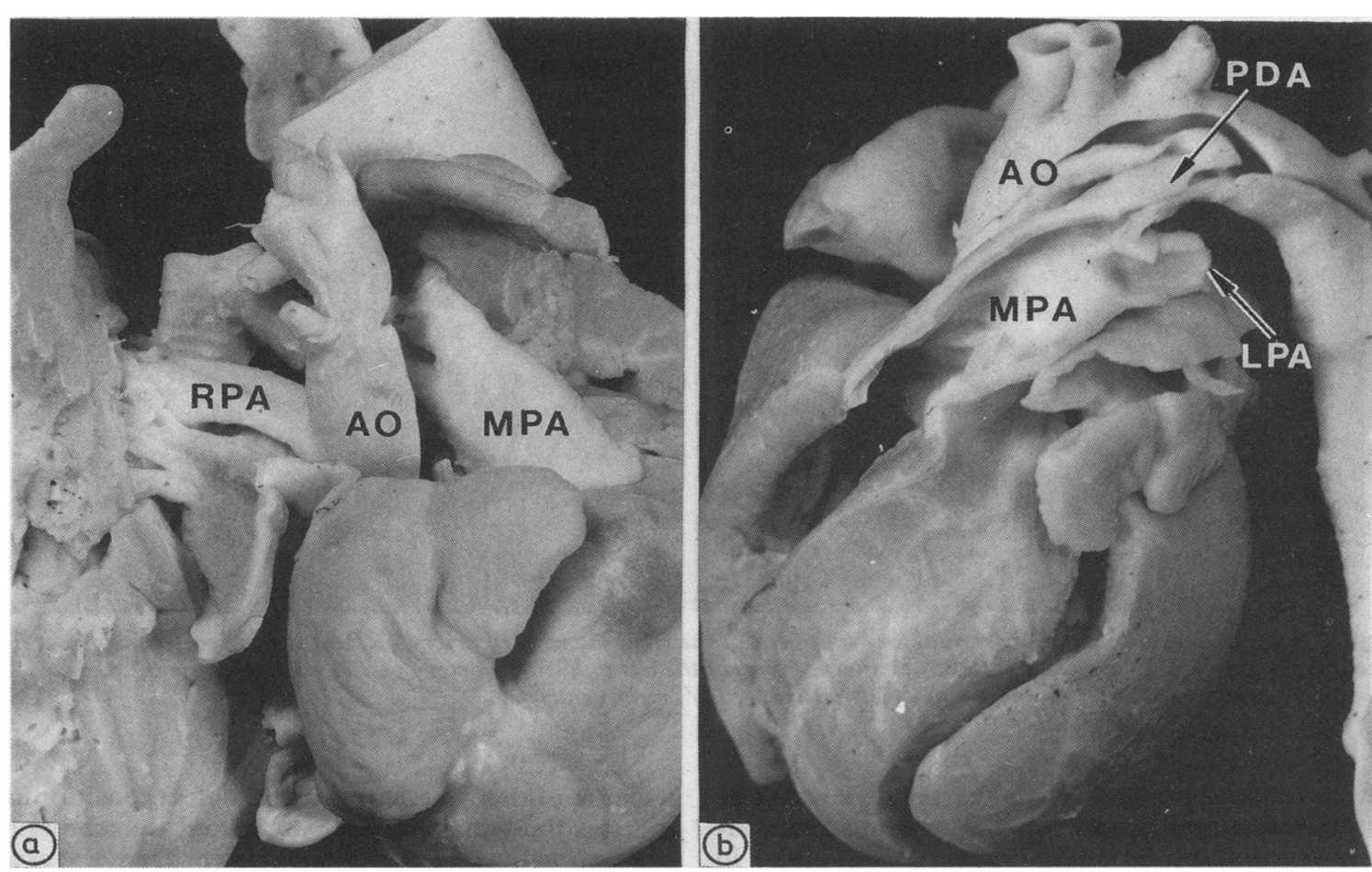

Fig 2 Necropsy specimen. (a) Anteroposterior view of the right pulmonary artery (RPA) arising from the posterolateral aspect of the ascending aorta ( $A O)$ (patient 1). (b) Left lateral view of the left pulmonary artery (LPA) and ductus arteriosus ( $P D A$ ) arising from the main pulmonary artery (MPA) (patient 1).

reach the right lung. The anomalous pulmonary artery, which was 4-11 $\mathrm{mm}$ in diameter at the hilum, was similar in size to the normally connected contralateral pulmonary artery in those patients without tetralogy of Fallot. In patients with tetralogy of Fallot there was a considerable disparity between the size of the anomalous pulmonary artery and hypoplastic pulmonary artery connected to the right ventricle. There was no stenosis at the origin of the anomalous pulmonary artery and it supplied all segments of the lung in all patients (fig $3 a$ ).

Three patients had a right aortic arch-both patients with tetralogy of Fallot and one patient who had an anomalous left pulmonary artery. An aberrant left subclavian artery arising from the descending aorta was found in two of the patients with a right aortic arch (fig 3b).

Patients with tetralogy of Fallot showed a typical intracardiac structure. There was a large malalignment ventricular septal defect with severe infundibular and pulmonary valvar stenosis (fig 4). The pulmonary artery connected to the right ventricle was hypoplastic, measuring from $30 \%$ to $60 \%$ of the opposite anomalous pulmonary artery. No remnarît of a second pulmonary artery arising from the pulmonary trunk was found.

The ductus arteriosus (arterial duct) was patent in the four patients without tetralogy of Fallot. connected the aorta to the left pulmonary artery the usual fashion when the arch was left sided (three patients). In the fourth patient, with a right aortie arch and anomalous origin of the left pulmonary artery, the duct passed from the aorta to the righ pulmonary artery.

\section{LUNG HISTOPATHOLOGY}

Examination of the lungs at necropsy in the tw infants (cases 1 and 2 ) who did not undergo operatiof showed normal pulmonary vasculature in both lungs, The infants died at 12 (case 1 ) and 23 (case 2) days age. Severe vascular changes were seen in the lungs supplied by the anomalous pulmonary artery in bor patients who died after repair of tetralogy of Fallot 25 and 26 months of age. Severe medial and intimg proliferation with focal fibrinoid changes were found in the medium and small sized arteries of the affected 

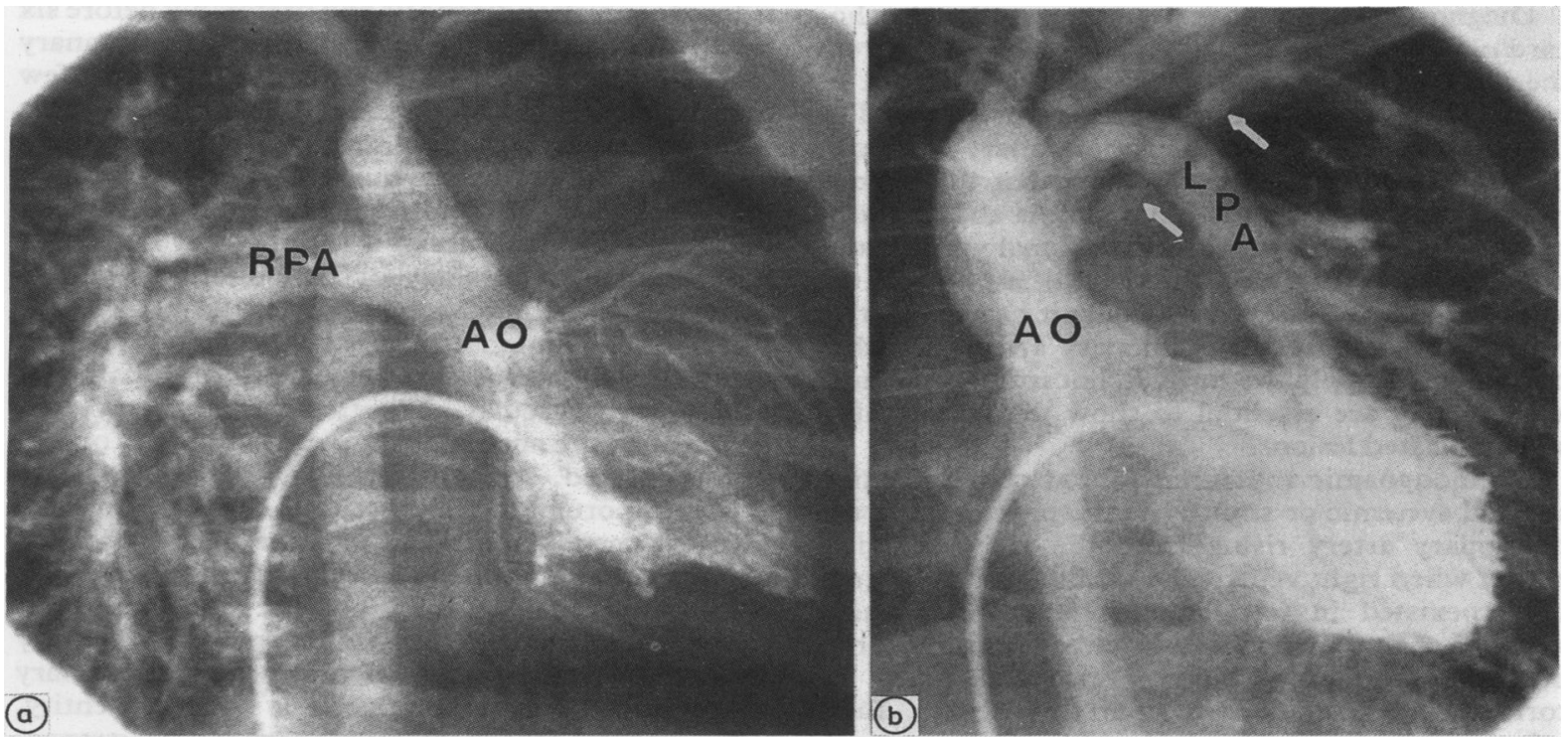

Fig 3 Left ventriculograms. (a) Right anterior oblique view of anomalous origin of the right pulmonary artery (RPA) from the ascending aorta (AO) (patient 6). (b) Anteroposterior view of another patient with anomalous origin of the left pulmonary artery (LPA) from the ascending aorta (AO), right aortic arch, and distal origin of the left subclavian artery (arrows) (patient 5).

lung. However, no evidence of pulmonary vascular disease was seen in the lung supplied from the right ventricle, because it was protected by pulmonary valvar and infundibular obstruction.

Biopsy, performed on both lungs of patient 6 who underwent surgical repair at one month and three

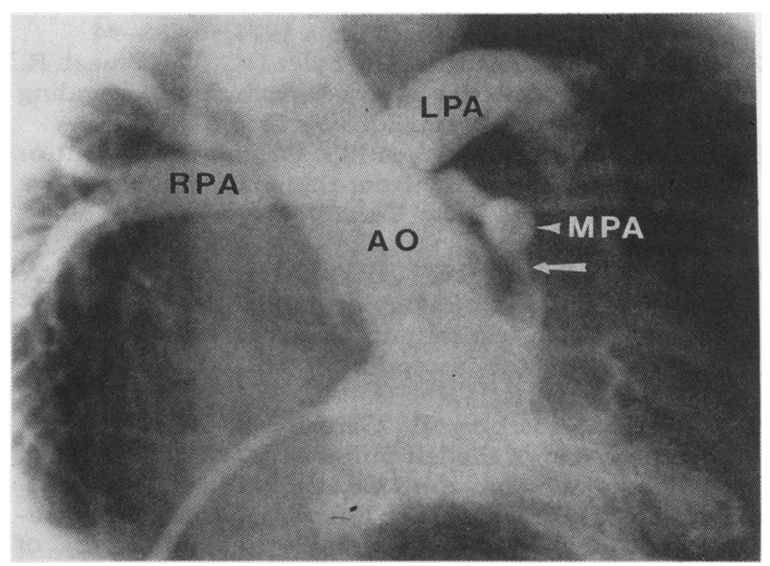

Fig 4 Right ventriculogram. Anteroposterior view of anomalous origin of the left pulmonary artery ( $L P A)$ from the ascending aorta $(A O)$. The right pulmonary artery (RPA) arises from a hypoplastic main pulmonary artery (MPA) with subpulmonary stenosis (arrow) (patient 3). weeks, showed only mild medial hypertrophy of the muscular pulmonary arteries without intimal or arteriolar changes. The appearances were similar in both lungs.

\section{Discussion}

Anomalous origin of a pulmonary artery from the ascending aorta is a distinct and well-recognised entity. ${ }^{12}$ It is a different malformation from pulmonary arteries that originate from the aorta via a ductus arteriosus or are supplied through collaterals between the systemic and pulmonary arteries. ${ }^{2}$ The morphology of the anomalous pulmonary artery from the ascending aorta is consistent. The artery arises from the posterolateral wall of the ascending aorta $5-30 \mathrm{~mm}$ above the ventriculoarterial junction. ${ }^{3}$ It can also arise from the opposite posterior aspect of the ascending aorta. ${ }^{4}$ The sizes of the anomalous artery and contralateral pulmonary artery are similar except when there is associated tetralogy of Fallot. Most commonly the right pulmonary artery is anomalously connected. ${ }^{13}$ Anomalous origin of the left pulmonary artery usually occurs with a right aortic arch, although it has been described with a left aortic arch in association with tetralogy of Fallot. ${ }^{45}$ Tetralogy of Fallot and arterial ducts are well recognised associations. An anomalous left subclavian artery with a right aortic arch is also seen. 
Diagnosis can be made by cross sectional echocardiography, ${ }^{67}$ when a posterior vessel arising from the ascending aorta and supplying the lung can be visualised in parasternal and suprasternal views. The finding can mimic an aortopulmonary window. Therefore it is important to show that the normal bifurcation of the pulmonary trunk is absent. Subcostal views may be helpful if the anomalous pulmonary artery arises from the lateral aspect of the ascending aorta, ${ }^{8}$ but more usually it has a posterior origin. The anomalous pulmonary artery branches normally to supply the lung. Echocardiography and angiography are essential to show the abnormality and associated lesions.

Haemodynamic measurements at catheterisation showed systemic or suprasystemic pressures ${ }^{9}$ in the pulmonary artery rising from the right ventricle except when right ventricular outflow tract obstruction coexisted in tetralogy of Fallot. Pulmonary vascular changes when seen at either necropsy or in intraoperative lung biopsy specimens can be correlated with delay in operative repair. Both infants in our series who died within the first month had normal pulmonary vasculature in both lungs. Lung biopsy at 1 month 3 weeks in the infant with suprasystemic pressures in the pulmonary artery that arose from the right ventricle showed only mild medial hypertrophy in the muscular arteries in both lungs. However, both patients with tetralogy of Fallot operated after two years of age had severe unilateral pulmonary vascular changes in the lung supplied by the anomalously connected artery. There was no evidence for pulmonary vascular hypertensive changes in the lungs directly supplied from the right ventricle and protected from excessive pulmonary blood flow by pulmonary and infundibular obstruction. A crossover mechanism of a circulating vasoconstrictor or neurogenic pulmonary hypertension ${ }^{210}$ from the anomalously supplied lung to the normally supplied lung was given as a possible cause of pulmonary vascular changes in the unaffected lung. However, pulmonary blood flow must clearly be a critical factor in the development of pulmonary vascular disease because patients with tetralogy of Fallot show unilateral changes. Some studies found no significant differences between the lungs on biopsy ${ }^{1011}$ while other studies showed more advanced changes on the non-affected side. ${ }^{12}{ }^{13}$ These changes were attributed to the high flow of fully oxygenated blood in the anomalously supplied lung.

Irrespective of the mechanisms, early surgical intervention, preferably before 12 months of age, is important to prevent the development of irreversible pulmonary vascular disease. ${ }^{14}$ In patients in whom the anomalous origin of the pulmonary artery is an isolated finding, operative correction should be con- sidered soon after diagnosis and preferably before siz months of age, because early changes of pulmonary. vascular disease can be identified in the first fe months of life. Correction may be possible with of without cardiopulmonary bypass depending upof which side the anomalous pulmonary artery rises and the technical difficulties encountered durin operation. ${ }^{2315}$ Surgical risk is increased by associate lesions such as tetralogy of Fallot, but successfull early surgical repair has been achieved. ${ }^{16}$ The hypo 0 plasia of the pulmonary artery connected to the right ventricle will influence the timing of repair but pulmonary vascular hypertensive changes will progress in the anomalously supplied lung if opera? tion is delayed.

It is important to make accurate diagnosis in earlgy infancy, particularly when patients have associate cardiac lesions such as tetralogy of Fallot. This dominating finding may obscure the importan associated anomalous origin of one pulmonary artery from the aorta. Anomalous origin of a pulmonar artery from the ascending aorta is a distinct entity different from other aortopulmonary arterial connec tions. There is rarely stenosis in the anomalou pulmonary artery and the lung with the anomalous supply is at high risk of the early development of pulmonary vascular hypertensive changes. Delay is 9 recognition of such a lesion may result in fatad pulmonary vascular disease.

\section{References}

1 Keane JF, Maltz D, Bernhard WF, Corwin RD, Nadas AS. Anomalous origin of one pulmonary artery from the ascending aorta. Circulation 1974;50:588-94.

2 Penkoske PA, Castaneda AR, Fyler DC, Van Praagh R: Origin of pulmonary artery branch from ascendin aorta. J Thorac Cardiovasc Surg 1983;85:537-45.

3 Kirklin JW, Barratt-Boyes BG. Origin of the right of left pulmonary artery from the ascending aorta. In? Cardiac surgery. New York: John Wiley and Sons 1986:939-44.

4 Calder AL, Brandt PWT, Barratt-Boyes BGT, Neutze JM. Variants of tetralogy of Fallot with absent pul monary valve leaflets and origin of one pulmonary artery from the ascending aorta. $A m J$ Cardiot 1980;46:106-16.

5 Robin E, Silberberg B, Ganguly S, Magnisalis $K_{\sigma}$ Aortic origin of the left pulmonary artery. Variant of tetralogy of Fallot. Am J Cardiol 1975;35:324-9.

6 Duncan WJ, Freedom RM, Olley PM, Rowe RD. Twost dimensional echocardiographic identification of hemitruncus: anomalous origin of one pulmonary artery from ascending aorta with the other pulmonarF artery arising normally from the right ventricle. A Heart $J$ 1981;102:892-6.

7 King OH, Huhta JC, Gutgesell HP, Ott DA. Two 
dimensional echocardiographic diagnosis of anomalous origin of the right pulmonary artery from the aorta: differentiation from aortopulmonary window. J Am Coll Cardiol 1984;4:351-5.

8 Smallhorn JF, Anderson RH, Macartney FJ. Two dimensional echocardiographic assessment of communications between ascending aorta and pulmonary trunk or individual pulmonary arteries. $\mathrm{Br}$ Heart $\mathrm{J}$ 1982;47:563-72.

9 Semb BKH, Bjornstad PG. Correction of isolated anomalous origin of the right pulmonary artery from the ascending aorta. Thorac Cardiovasc Surg 1981;29:255-8.

10 Griffiths SP, Levine OR, Anderson DH. Aortic origin of the right pulmonary artery. Circulation 1962;25: 73-84.

11 Porter DD, Canent RV, Spach MS, Baylin GJ. Origin of the right pulmonary artery from the ascending aorta. Unusual cineangiographic and pathologic find- ings. Circulation 1963;27:589-93.

12 Weintraub RA, Fabian CE, Adams DF. Ectopic origin of one pulmonary artery from the ascending aorta. Radiology 1966;86:666-76.

13 Yamaki S, Suzuki Y, Ishizawa E, Kagawa Y, Horiuchi $T$, Sato $T$. Isolated aortic origin of right pulmonary artery. Report of a case with special reference to pulmonary vascular disease in the left and right lungs. Chest 1983;3:575-8.

14 Benatar A, Kinsley RH, Milner S, Dansky R, Hummel DA, Levin SE. Surgical correction for one pulmonary artery arising from ascending aorta-report of five cases. Int J Cardiol 1987;16:249-55.

15 Sibley YDL, Roberts KD, Silove ED. Surgical correction of anomalous origin of right pulmonary artery from aorta in a four day old neonate. Br Heart $J$ 1986;56:98-100.

16 Morgan JR. Left pulmonary artery from ascending aorta in tetralogy of Fallot. Circulation 1972;45:653-7. 